\title{
What makes killing wrong?
}

\author{
Walter Sinnott-Armstrong, ${ }^{1,2}$ Franklin G Miller ${ }^{2}$
}

${ }^{1}$ Department of Philosophy and Kenan Institute for Ethics, Duke University, Durham, North Carolina, USA

${ }^{2}$ Department of Bioethics, National Institutes of Health, Bethesda, Maryland, USA

\section{Correspondence to}

Walter Sinnott-Armstrong,

Kenan Institute for Ethics, Duke University, Box 90432, Durham, NC 27708, USA

ws66@duke.edu

The opinions expressed here are those of the authors and do not reflect the position or policy of the National Institutes of Health, the Public Health Service or the Department of Health and Human Services.

Received 2 November 2011 Revised 13 December 2011 Accepted 16 December 2011 Published Online First 19 January 2012

- http://dx.doi.org/10.1136/ medethics-2012-100570

- http://dx.doi.org/10.1136/ medethics-2012-100651

- http://dx.doi.org/10.1136/ medethics-2012-100652

http://dx.doi.org/10.1136/

medethics-2012-100807

http://dx.doi.org/10.1136/

medethics-2012-100948

\section{ABSTRACT}

What makes an act of killing morally wrong is not that the act causes loss of life or consciousness but rather that the act causes loss of all remaining abilities. This account implies that it is not even pro tanto morally wrong to kill patients who are universally and irreversibly disabled, because they have no abilities to lose. Applied to vital organ transplantation, this account undermines the dead donor rule and shows how current practices are compatible with morality.

Imagine that Abe robs Betty and shoots her in the head so that she will not testify against him if he is caught. As a result, Betty dies. It is clearly immoral for Abe to shoot Betty. Why?

The most general explanation is that Abe harmed Betty-his act resulted in bad effects for Betty. Other explanations are possible, of course. Some theorists might claim that what makes Abe's act wrong is Abe's intention, but the reason why Abe's intention makes his act wrong is that it was an intention to cause harm to Betty, so the wrongness of the intention is still grounded in the badness of the effect that was intended. Other theorists might instead say that Abe violates Betty's rights, but her violated right in this case is a right not to be harmed, so again the bottom line is about harm. Still others might propose that Abe shows disrespect for Betty's autonomy or personhood, but what makes his act disrespectful is that it inflicts a loss of autonomy, and a loss of autonomy is a kind of harm, broadly construed, so what makes killing wrong is still that Abe's act had some harmful or bad effect on Betty.

Nonetheless, it is not enough to say that Abe harmed Betty. We still need to know which kinds of effects count as harms. That question is not simple, as we will see. Another reason is that, even if the fact that Abe harmed Betty explains why his act was wrong, it does not explain how wrong it was-its degree of wrongness. After all, some harms are minor. To fully explain what was wrong with Abe's act, we need an explanation that captures the full extent of what was wrong with his act.

Which effect explains that? Abe's act causes at least two effects on Betty. One is death-the loss of life. The other effect, which is less often noticed, is total disability. Shooting Betty makes her unable to do anything, including walking, talking, and even thinking and feeling. Since Betty then lacks all abilities to act or do anything, and we are concerned here only with abilities to act or do things, Betty's disability is universal. Of course, anaesthesia can also cause universal disability for a short time. In contrast, the universal disability that Abe's shooting causes is also irreversible.
Universal and irreversible disability will be called total disability.

Which of these consequences-death or total disability-makes Abe's act of shooting immoral? Two answers are possible. In one view, Abe's act is immoral because this shooting causes death, so it is an act of killing, and killing is immoral unless it is justified, which it is not in this case. In another view, Abe's act is immoral because it causes total disability, so it is an act of total disabling, and total disabling is immoral unless it is justified, which it is not in this case. ${ }^{i}$ These two views are rarely separated, because to kill normal people like Betty is to disable them totally. Conversely, there was no way to totally disable Betty without killing her prior to the advent of the intensive care units in which the lives of totally disabled people can be sustained by mechanical ventilation and artificial hydration and nutrition along with other techniques. Nonetheless, these views remain distinct, because today Abe can totally disable Betty without killing her. He can shoot her in the head so as to cause irreversible brain damage that makes her unable to walk, talk and even think and feel without also causing her death, because her life can be sustained artificially.

\section{TOTAL DISABILITY EXPLAINS THE WRONGNESS OF KILLING}

Which of these two views is correct? To decide that issue, imagine that Abe's bullet does not kill Betty but instead causes brain damage that leaves Betty conscious but totally unable to control any of her actions or even her thoughts or experiences. She is worse off than people with locked-in syndrome because they can control their thoughts, but she cannot. She has a mental life, but it is a "blooming, buzzing confusion" ${ }^{1}$ that Betty cannot control at all. Colours and shapes appear in random order and location in her visual field, like a constantly changing Mondrian (except that it is not beautiful), and she cannot control or affect that experience in any way. She cannot talk to anyone or even think of anyone or even try to think of anyone or anything. To isolate the issue of death versus total disability, let us also assume for now that Betty feels no pain and takes no pleasure in any of what goes on in her mind and that her experiences do not fulfil or frustrate any of her desires or correspond in any meaningful way to the outside world. Her experiences and thoughts just continue chaotically and uncontrollably but neither painfully nor

'To say that Abe disabled Betty is not to say that Abe changed Betty from able-bodied to disabled, since Betty might have been disabled before being shot. Instead, to say that Abe disabled Betty is just to say that he reduced her level of ability by causing her to lose an ability that she previously had or gain a disability that she did not previously have. 
pleasantly. In this situation, Betty has mental states, at least intermittently and temporarily, so she is not dead by any standard or plausible criterion. Still, she is universally disabled because she has no control over anything that goes on in her body or mind. Like death, her state is irreversible. It is not permanent, because one day her mental states will cease and then she will die. But for now she is alive but totally disabled.

In this case, is Betty any better off totally disabled than dead? If so, then death must involve the loss of something valuable beyond the loss of all abilities forever. If not, then death does not involve the loss of anything valuable beyond what is lost in total disability. Death is still distinct from total disability, but it is no worse.

This comparative value judgement partly determines whether death or total disability provides the best explanation of why Abe's act of shooting is immoral. If death is worse than total disability, then the fact that Abe's act causes total disability cannot fully explain what is wrong with Abe's act, because his act causes more loss in value than just total disability. In contrast, if death is not any worse than total disability, then the fact that Abe's act of killing causes total disability would seem to fully explain what is wrong with Abe's act of killing, since there is nothing else to make it wrong beyond the loss of value involved in total disability.

Our intuitions about this case seem clear. We see nothing to make Betty's death worse than her total disability. This intuition seems to be widely shared, since many people dread death no more than and for the same reasons that they would dread total disability. There is nothing to be dreaded about death that wouldn't also be dreaded about total disability. Indeed, one of us even finds it plausible to see total disability as worse than death, because there is disvalue in a disordered state of consciousness with no control over experiences. In any case, Betty is not worse off dead. In our view, then, what explains the wrongness of Abe's act of killing Betty is not that he caused her death but only that he caused her total disability.

Another possible explanation is that Abe caused Betty to lose consciousness permanently. ${ }^{2}$ That loss is different from death because patients can remain alive even while they are unconscious. It also differs from Betty's total disability because she remained conscious while lacking any ability to control any of her mental states or anything that goes on in her consciousness. Assuming as before that Betty does not feel pleasure or pain, our intuitions again suggest that Betty is no worse off unconscious than she is conscious but totally disabled and so unable to control anything that goes on in her consciousness. There is nothing to be dreaded about unconsciousness that wouldn't also be dreaded about total disability with consciousness. Hence, what explains the wrongness of Abe's act of killing Betty is not that he caused her permanent loss of consciousness but only that he caused her total loss of ability.

One advantage of this position is that it simplifies the structure of morality. The moral rule 'Don't kill' is a basic part of almost every popular ethical system, even though it has to be qualified with something like '... without an adequate reason'. However, almost everyone also agrees that it is wrong to disable - that is, to blind, deafen, paralyse and so on-again '... without an adequate reason' ${ }^{\text {ii }}$ Indeed, almost everyone would agree that the wrongness of disabling varies with the degree of disability caused-for example, causing a person to be deaf and blind is worse than causing them to be only blind. A moral

iiThe notion of ability plays a large role in several recent ethical theories, including those found in Sen, Nussbaum and Pettit. ${ }^{3-5}$ theorist thus faces a choice: either have two basic rules (both 'Do not kill' and 'Do not disable') or only one basic rule ('Do not disable' $)^{\text {iii }}$. We assume for now that nobody wants to have only the rule against killing but no rule against disabling, because then it would not be morally wrong for Abe to blind or totally disable Betty or any potential witness without killing her. We also assume that any moral system with a basic rule against disabling can also include some derived rule against killing in cases where killing causes disabling, and this derived rule will prohibit almost all (although not all) cases of killing. So, should a moral theory have both basic rules or only one? Of course, having only one basic rule makes a theory simpler, but it can still be better overall to have the two rules if the second rule is needed to explain and justify certain moral judgements. However, it is not clear what work is done by the rule against killing if the rule against disabling is already in place. If Betty is no worse off being dead than being totally disabled, as we suggested, then it does not seem any worse to kill Betty than to totally disable her (and possibly worse to totally disable her than to kill her). The rule against disabling then fully explains all that is bad and wrong with Abe's act of killing, and there is no need to add a separate rule against killing. Without any need for complication, simplicity wins.

\section{OBJECTIONS}

Traditionalists might object that morality still needs a rule against killing because it would be wrong to kill Betty after she became totally disabled. But why? If Betty is no worse off being dead than being totally disabled, then it does not seem any worse to kill Betty than to totally disable her. And then killing her does not make her worse off if she was already totally disabled. But if killing her does not make her worse off, then why is it bad to kill her? We are assuming that Betty did not leave any advance directive to keep her alive in a totally disabled state. ${ }^{\text {iv }}$ Then killing her cannot disrespect her autonomy, because she has no autonomy left. It also cannot be unfair to kill her if it does her no harm. Of course, opponents will claim that life is sacred or that killing her violates God's commandment, but why would God forbid us (or have any reason to forbid us) to do something that does not make Betty worse off? Similarly, secular theorists might claim that life has sanctity or intrinsic value ( $\mathrm{cf}^{\mathrm{D}}$ workin ${ }^{6}$ ), but why is life valuable in this extreme case when it includes no ability (or pleasure, as we are still assuming)?

Critics might respond that we are focusing too much on consequences when what matters to morality is instead intentions. However, if Abe's intention is only to prevent Betty from testifying against him, then his intention can be fulfilled by totally disabling her without killing her. He might have planned to totally disable her by means of killing her, since he probably did not think about totally disabling her without killing her. Then he intended her death as a means of silencing her. Nonetheless, he also intended to disable her as a means to the same end. This intention to disable seems to be the one that is

iiiiBoth of these rules are usually meant to exclude (a) intending to cause death or disability even if the attempt fails and (b) causing an increase in the risk of death or disability even if that risk is never actualised, but we will ignore those complications here.

ivlt would be wrong to go against a valid advance directive for the same reasons why it would be wrong to cremate the body of someone who asked to be buried. That does not mean, however, that authorisation is required for killing the totally disabled. In the absence of any advance directive one way or the other, it is no more wrong to kill the totally disabled than to cremate the body of someone who gave no advance directions about cremation or burial. 
essential to his plan. Killing her is not necessary for his purposes, because his goals can be fully met without killing her by totally disabling her. What if his motivation was not to avoid prosecution but was only to harm her because he hated her and wanted her dead? He still might be satisfied if she were totally disabled but left alive as long as he thinks that being totally disabled is just as bad as being killed. He just didn't think of disabling without killing and did not know how to do that. He might not be satisfied if he wants to send her to Hell as soon as possible and if he believes that people do not go to Hell until they die. Nonetheless, for a wide variety of purposes, given common beliefs, if Abe's intention (rather than the actual result) is what makes his act wrong, then it still seems enough to refer to his intention to disable her without referring at all to his intention to kill her or cause her death.

Another possible response is that killing Betty will harm other people. It is horrible to have a loved one die or be killed. However, it is just as horrible (if not worse) to have a loved one irreversibly and totally disabled. What if Betty is already totally disabled. She already has no control over anything in her life, including her thoughts, feelings and other mental states, and her condition is irreversible. In that case, it is not obvious that Betty's friends would feel any worse or be harmed any more if Betty lost her life without losing any ability (since she has no ability to lose). Even if they did feel worse, it is not clear what reason they would have to feel worse. Hence, it is hard to see how the effects of killing Betty on other people could make it wrong to kill Betty after she becomes totally disabled. There might still be concerns about killing her without authorisation. However, there are similar concerns about performing autopsies or taking organs from corpses without authorisation. These kinds of concerns do not show that killing her would be a wrong to Betty.

Traditionalists still might appeal to tradition. After all, every major religious tradition and every major moral theory includes some rule like 'Don't kill'. ' How could they all be wrong? They might be oversimplifying for legitimate pedagogical reasons. When teaching our children, most of us say things like, 'Don't cross a street without an adult'. We do not add '... unless a tiger is chasing you' or even '... unless the street is closed to traffic for a festival'. It is better pedagogical practice to omit the exceptions because it is almost always more dangerous for a child to cross a street without an adult. The exceptions are so rare that adding them into the rule will make it more likely that children will cross dangerous streets without an adult than it will save their lives by making them quicker to cross a street to get away from a tiger. Analogously, moral traditions might formulate the rule simply as 'Don't kill' for legitimate pedagogical reasons in order to reduce mistakes. After all, it is extremely rare to totally disable anyone without killing them. Indeed, this was not possible until recently. So there might have been real pedagogical value to expressing the seriousness of such extreme acts by stating a separate rule against killing. Still, pedagogy is not philosophy-not even in ethics - so the rule 'Don't kill' might have no place in philosophical moral theory even if it does have a role in moral pedagogy.

Moreover, it is not clear whether the traditions that say 'Life is sacred' or 'Killing is wrong' really believe what they say. The

\footnotetext{
${ }^{\vee} \mathrm{A}$ better translation of the biblical commandment might be 'Thou shall not commit murder' (which seems tautological), but 'Thou shalt not kill' is more common. In any case, our response applies to either translation insofar as murder requires killing. Notice also that Buddhist and other Asian religious traditions also endorse rules against killing, so this part of morality is not a Western peculiarity.
}

point is not (just) that these traditions also justify killing in selfdefence or war as well as capital punishment. That might be explained by the qualification '... without an adequate reason'. Instead, the point here is about whether the tradition really means 'life' and 'killing'. If life were really what is sacred, then all life would be sacred. But nobody believes that-not even Jains. After all, weeds are alive. Hence, if killing were wrong just because it is causing death or the loss of life, then the same principle would apply with the same strength to pulling weeds out of a garden. If it is not immoral to weed a garden, then life as such cannot really be sacred, and killing as such cannot be morally wrong. Of course, what people mean when they say 'Don't kill' is 'Don't kill humans' (or maybe 'Don't kill sentient animals'). But why then are humans (or sentient animals) singled out for moral protection? The natural answer is that humans (and sentient animals) have greater abilities than plants, and those abilities give human lives more value. Humans can think and make decisions as well as feel (an ability that they share with sentient animals). But if these abilities are what make it immoral to kill humans (but not weeds), then what really matters is the loss of ability when humans (but not weeds) are killed. And then the view that human life is sacred does not conflict with-and might even depend on-the view that what makes life sacred (if it is) is ability, so the basic moral rule is not 'Don't kill' but is instead 'Don't disable'.

Admittedly, religious ethicists might reply that human life is sacred and the life of weeds is not sacred because God created humans in His (Her?) image or chose us as His (Her?) special people or because God commanded us not to kill other humans (as in the Ten Commandments) but did not command us not to kill weeds (and reportedly gave us the plants and animals to serve our needs). However, these arguments will have no force at all for those of us who prefer our moral theories to be independent of religion. One reason for this preference is that other religious traditions believe in different commands. Buddhists also say 'Don't kill' but many Buddhists-and there are a lot of them-do not mean only 'Don't kill humans' and they do not view only human life as sacred, perhaps because they believe that some humans were reincarnated as animals (although maybe also because they emphasise the ability to suffer over the ability to think). Thus, without depending on a special religious tradition, one cannot pick among moral rules about killing (except by referring to abilities). That dependence on religious beliefs makes such rules problematic at least in philosophical theory and public policy in any religiously diverse society.

Instead of defending the rule against killing, other opponents might reject the rule against disabling. Some might fear that this rule will reinforce negative stereotypes of people with disabilities or even foster a belief that people with profound disabilities are better off dead. We oppose such views, of course, and nothing like this follows from the rule against disabling. One obvious reason is that people who have some disabilities still have many other valuable abilities. They are very far from being totally disabled. The rule against disabling implies that it would be wrong to remove or reduce their remaining abilities. Furthermore, some disabilities are due to society. People who use wheelchairs find it difficult to enter buildings without ramps. Blind people find it difficult to cross city streets at intersections when walk signals are silent. For the government to put up buildings without ramps or walk signals without sound is then to make people who need them less able than they would otherwise be. If this counts as causing a disability, which seems plausible, then the rule against disabling tells us why the government needs to do more for disabled persons. And the 
same point applies to individuals and businesses. The rule against disabling could, thus, be used to help disabled people.

Another likely objection is that, if disabling is what is bad about death and what is wrong with killing, then, since some lives include more abilities than others, some people's lives have more value and it is worse to kill some people than others. In a triage case, if we could save only one of two people, and if one had significantly more abilities than the other, then the disability view might seem to suggest that we morally ought to save the person with more abilities. These supposed implications feel very bad for historical as well as philosophical reasons.

Luckily, the disability view has several ways to respond. One could hold that the value of a person does not vary after abilities (including future abilities) pass a minimal threshold that is above plants. ${ }^{7}$ One could also hold that the value of equality and justice overrides any difference in the value of lives and makes it morally wrong to treat people differently even if they have different abilities. Yet another possibility is to argue that some disabilities are often overridden by other abilities, so comparisons are difficult or impossible, and we cannot really know which person has more ability in most realistic cases. One could instead or in addition argue that our moral duty is to honour (or not to disrespect) the value of abilities rather than to promote ability, and that the prohibition on disrespect ensures equality and justice. ${ }^{9}$ And, of course, one could admit that people's remaining lives do differ in value, so it is worse to kill some people than others, but one could still (try to) show that these implications are not as unpalatable as they might appear at first. ${ }^{10}$ We will not choose among these responses. It is enough here to show that the disability view has several replies to this objection.

Moreover, the competing view faces the same problems. If there are two rules ('Don't kill' and 'Don't disable'), then the killing rule might not create inequality, because everyone who is alive is equally alive; but the disability rule still creates the same problems of equality as it does in a moral theory where it is the only rule. As long as disabilities are bad, lives with more disability seem less good overall, and it seems worse to cause more disabilities than to cause less. Whether this implication is accepted or avoided, it is just as much of a problem for a moral theory with both killing and disability rules as it is for a moral theory with only the disability rule and no killing rule.

Indeed, even the rule 'Don't kill' runs into problems of equality if it is wrong to kill because it is wrong to cause loss of life. After all, some people have more life left than others. Causing death is usually just shortening life, since we will all die someday. But then, if it is bad to shorten life, it is presumably worse to shorten it more, and greater shortening is worse because more life is better than less life. That implies that young people's lives have more value than old people's lives, since the young have more life left. Thus, the rule against killing cannot avoid the problems of equality that the disability rule faces, so those problems of equality do not justify adding the killing rule to the disability rule.

Of course, disability is not all that matters. Our point is only that there is nothing bad about death or killing other than disability and disabling. Other values can still matter to other comparisons. For example, pain and pleasure (or desire satisfaction) can matter too, so that pleasant consciousness without any ability is valuable. Then, if Betty feels pleasure, that could make it immoral to kill her, even if she is irreversibly and totally disabled. Of course, it would take a lot of work to figure out how pleasure and pain can be weighed against ability, especially when comparing abilities, pleasures and pains in different persons. We will not address those problems here, except to say that adding the killing rule will not help and might even complicate the project of moral theory, because then it will be not only ability but also life that needs to be weighed against pleasure and pain.

We also admit that our talk of disability needs to be sharpened. What exactly is disability ${ }^{11}$ How do disabilities differ from inabilities? Is it ability, capacity, capability, power or control, or something else that really matters morally? How do future abilities weigh against present abilities? Again, we will not address these problems here, except to say that a theory with both the disability and killing rules will have just as much trouble with these difficult issues.

\section{APPLICATION TO ORGAN TRANSPLANTATION}

We will close with one application to show that our approach makes a difference to medical practice. Traditional medical ethics embraces the norm that doctors (and other healthcare professionals) must not kill their patients. This norm is often seen as absolute and universal. In contrast, we have argued that killing by itself is not morally wrong, although it is still morally wrong to cause total disability.

Abandoning the norm prohibiting killing has important implications for a variety of moral issues, but here we will discuss only one example: practices of vital organ donation. The established legal and ethical prerequisite for vital organ donation is known as 'the dead donor rule': vital organs, such as the heart, both lungs and both kidneys, cannot legitimately be procured from a donor unless the donor is already dead. The dead donor rule fundamentally reflects the application of the norm that doctors must not kill. In actual practice, however, donors of vital organs are not dead-or not known to be dead-at the time when organs are procured.

The primary source for vital organs consists of individuals with traumatic brain injury who are diagnosed with 'brain death' or 'total brain failure'. Although legally dead, these individuals maintain a wide range of vital functioning of the organism as a whole, at least with the aid of mechanical ventilation and other intensive care interventions. These vital functions include circulation, respiration, digestion and metabolism, temperature control, fighting infections, wound healing and gestation of fetuses for up to 3 months in pregnant women. Whereas these unfortunate individuals are totally disabled (as well as permanently unconscious), their bodies remain alive.

A secondary and growing source of vital organs is from neurologically damaged (but not 'brain dead') patients determined to be dead following withdrawal of life-sustaining treatment. A short interval after the heart stops beating (typically $2-5 \mathrm{~min}$ ), the patient's death is declared and organs are procured. However, cessation of circulation and respiration must be irreversible to warrant a determination of death. While circulation and respiration will not start up again on their own in this situation, in many cases cardiopulmonary resuscitation could restore these functions at least for a short period of time. Thus, the criterion of irreversibility has not been satisfied; hence, these patients are not known to be dead at the time of organ procurement. $^{12-15}$

In such cases, the dead donor rule is routinely violated in the contemporary practice of vital organ donation. Consistency with traditional medical ethics would entail that this kind of vital organ donation must cease immediately. This outcome would, however, be extremely harmful and unreasonable from an ethical point of view. 
Luckily, it is easily obviated by abandoning the norm against killing. Although still living (or at least not known to be dead), vital organ donors in the contemporary practice of transplantation are totally disabled at the time of organ procurement, owing either to the profound brain injury characteristic of the diagnosis of 'brain death' or to the cessation of heart beating following withdrawal of life support. The fact that the lives of the former could be sustained and the latter could be revived by mechanical means does not show that they have the ability to control anything themselves. All it shows is that medical devices have an ability to keep them alive. They stand at an irreversible point of no return, with no prospect of regaining any of the human abilities that make a life worth living. Although not dead, these patients are as good as dead in view of their total disability. Consequently, no harm or wrong is done to them by vital organ procurement, after which they will become dead. Moreover, given prior plans to withdraw life support for patients in both of these pathways to vital organ donation, the patients would become dead rapidly following withdrawal of life support regardless of whether organs were procured. Hence, no one is made dead in the process of organ procurement who would not otherwise be dead following treatment withdrawal.

Traditionalists have tried to square current practices of vital organ donation with the dead donor rule by redefining death, using neurological criteria for death and fudging the requirement of irreversibility. These moves are dubious for many reasons discussed elsewhere. ${ }^{16}$ Such moves have been accepted by traditionalists only in order to make vital organ transplantation comply with the standard norm against killing. Once we recognise that the prohibition of killing has no moral force independent of disability, we can focus on the ethically relevant question: When is it morally justifiable to procure vital organs? In view of a biological definition of death and sound criteria for its application, we never actually procure vital organs from dead donors. Fortunately, it is not ethically necessary for vital organ donors to be dead. It suffices for them to be totally disabled, with no prospect of recovery of any human abilities or experience. According to this standard, our current practices of vital organ transplantation are ethically justified.

Making transplantation practices consistent with the law relating to homicide and with public opinion still poses daunting practical challenges. ${ }^{16}$ But notice that there would be no incoherence in permitting vital organ donation from still living patients who are totally disabled while continuing to prohibit active euthanasia of patients who are not totally disabled. Policy considerations relating to the prospect of mistake and abuse arguably might continue to justify legal prohibition of active euthanasia outside the context of vital organ donation restricted to totally disabled patients who are 'brain dead' or whose organs are procured after a circulatory determination of death.

Critics might object that abandoning the dead donor rule will take us down the slippery slope to procuring vital organs from the mentally retarded or other groups of vulnerable individuals with disabilities. Absolutely not. We can hold the line for vital organ donation by continuing to restrict it to those in a state of total (universal and irreversible) disability. It is only these donors who would not be harmed or wronged by vital organ donation, since all other donors have abilities to lose. Likewise, self-sacrificing vital organ donations (say, from healthy parents who want to save their children in need of such organs to survive) need not be accepted when the rule against killing and the dead donor rule are abandoned, because these self-sacrificing donors are sacrificing their health and abilities, whereas our practical proposal applies only to totally disabled donors. ${ }^{\text {vi }}$

A final objection: 'Your radical departure from traditional morality and medical ethics suggests that you are radically wrong'. As philosophers committed to fallibilism, we recognise this possibility. However, having laid out our arguments for conceiving morality and medical ethics without a norm prohibiting killing, we submit that the burden of proof is on our critics to demonstrate where and how we have gone astray.

Acknowledgements We are grateful to Christine Grady and Luana Colloca for helpful discussions and comments on a draft.

Competing interests None.

Provenance and peer review Commissioned; internally peer reviewed.

\section{REFERENCES}

1. James W. Principles of Psychology. Cambridge, MA: Harvard University Press, 1981:462.

2. Lippert-Rasmussen K. Two puzzles for deontologists: life-prolonging killings and the moral symmetry between killing and causing a person to be unconscious. J Ethics 2001;5:385-410.

3. Sen A. The Idea of Justice. Cambridge, MA: Harvard University Press, 2009, Chapters 11-14.

4. Nussbaum M. Creating Capabilities: The Human Development Approach. Cambridge, MA: Harvard University Press, 2009.

5. Pettit P. Republicanism: A Theory of Freedom and Government. New York, NY: Oxford University Press, 2000.

6. Dworkin R. Life's Dominion: An Argument About Abortion, Euthanasia, and Individual Freedom. New York, NY: Knopf, 1993

7. Rawls J. A Theory of Justice. Cambridge, MA: Harvard University Press, 1973:504-12.

8. MacMahan J. The Ethics of Killing: Problems At the Margins of Life. New York, NY: Oxford University Press, 2003:232-66.

9. Pettit P. The consequentialist perspective. In: Baron MW, Pettit P, Slote M, eds. Three Methods of Ethics. Oxford: Blackwell, 1997:126-9.

10. Lippert-Rasmussen $\mathbf{K}$. Why killing some people is more seriously wrong than killing others. Ethics 2007;117:716-38.

11. Savulescu J, Kahane G. The welfarist account of disability. In: Cureton A, Brownlee K, eds. Disability and Disadvantage. Oxford: Oxford University Press, 2009:14-53.

12. Truog RD. Is it time to abandon brain death? Hastings Cent Rep 1993;27:29-37.

13. Shewmon DA. Chronic brain death-meta-analysis and conceptual consequences. Neurology 1998;51:1538-45.

14. Shewmon DA. The brain and somatic integration: insights into the standard biological rationale for equating 'brain death' with death. J Med Philos 2001;26:457-78.

15. Marquis D. Are DCD donors dead? Hastings Cent Rep 2010;40:24-31.

16. Miller FG, Truog RD. Death, Dying, and Organ Transplantation. New York: Oxford University Press, 2012:52-79, 97-112, 147-52.
viOur position also does not make it any easier (or harder) to justify euthanasia, since patients who might be euthanised are not totally disabled, so they have some abilities to lose. 